\title{
The Arrangement of Open Space on Lamongan City Center based on Smart City Concept
}

\author{
Yusuf Khoirul Munzilin', Bambang Soemardiono² and Asri Dinapradipta²
}

${ }^{1}$ Postgraduates Student, Department of Architecture, Faculty of Architecture, Design and Planning, Sepuluh Nopember Institute of Technology, Surabaya, East Java, Indonesia.

${ }^{2}$ Department of Architecture, Faculty of Architecture, Design and Planning, Sepuluh Nopember Institute of

Technology, Surabaya, East Java, Indonesia

\begin{abstract}
At this time the city center is used as a benchmark in seeing the development of a city, including the City of Lamongan. The Lamongan City Center has quite high accessibility and activities, this is due to the presence of important buildings, government buildings and pavilion, Lamongan-level markets, places of worship and town squares. However, the central area of Lamongan City has not been able to optimize the potential of open space as a support for the city center, this is because there are problems related to environmental quality, functional and visual quality of supporting elements of urban space. This research aims to organize the open space with the application of the Smart City concept that integrates human, environment and technology. This research uses Character Appraisal analysis techniques to measure the quality of the open environment and Triangulation to reduce the validity of the data. The results of this research indicate that the center of Lamongan City has functional and vi sual problems related to infrastructure and environmental elements, so it has not been able to realize the concepts of Smart City, especially on the concept of Smart Mobility, Smart Living, Smart Environment and resulted in a decrease in the quality of open space in the Lamongan city center, this has an impact on the decline of the community in their activities in the open space of the center of Lamongan City.
\end{abstract}

Key Words: Open Space, Space Quality, Arrangement, Smart City, Smart Mobility, Smart Living, Smart Environment.

\section{INTRODUCTION}

Lamongan City Center has high accessibility and activities, this is due to the existence of various important buildings in the form of government buildings, Lamongan markets, places of worship and town squares. The existence of high accessibility and activities in the city center is not supported by city facilities and infrastructure, especially on the open space part of the city center. The urbanist phenomenon in urban areas should be supported by the construction of physical facilities and infrastructure and improving the existing city structure, so that the possibility of urban problems and a decrease in the ability to service facilities and infrastructure can be avoided [1].

Problems in the Lamongan city center space related to the functional and visual quality of the physical aspects of the open space of the city center namely: the poor system of human movement in the open space in the absence of adequate public transportation, disruption of vehicle and pedestrian pathways by the presence of illegal parking and street vendors, the lack of community service facilities to support activities in open spaces such as the absence of road benches, poor quality lighting at $n$ ight and the lack of order on the existing boards, in addition to the lack of handling and utilization of rubbish waste and water waste with poor maintenance of existing vegetation in the open space of Lamongan downtown. Basically in supporting the development of the city, the Lamongan City government has had a Long-Term Development Plan (RPJPD), which has the characteristics of focusing on identifying and handling strategic issues with dynamic targets, following new trends, and more oriented towards anticipatory action [2]. Based on the characteristics of the RPJPD, strategic issues with new trends, the City Government of Lamongan is one of the cities leading to Smart City with the signing of the MoU in mid-2018 in Jakarta [3].

This research contributes to the development of the city, by improving the functional and visual quality of the physical aspects of the open space in supporting the development of the city center. This research is based on problems related to the 
physical aspects of the open space of the city center by solving problems applying the Smart City concept, thus this research can be used as a reference in overcoming the problems of open spaces the city center.

\section{LITERATURE REVIEW}

Arranging the open space to support the downtown area that has high accessibility and activity, as well as important buildings requires a theory that is relevant to the urban design discipline as well as theories related to the focus of the research topic. The theoretical study begins with the main theory of the elements of urban design by Hamid Shirvani (1985), the theory as the main theory for the direction of the arrangement of the open space of the central area of Lamongan City, in addition this research is also supported by theories related to the focus of research, namely open space, aspects of open space and theory that refers to the basic concept approach to structuring the Smart City.

\subsection{The Urban Design Process}

The purpose of the city design is to restore and improve the physical quality that includes the functional and visual space of the city, so that the city will be more suitable for living and can support the life of the city community. Based on the theo ry of city forming, there are eight urban elements that can help improve urban quality: Land use, building forms and groups, open spaces, parking and circulation, markers, pedestrian paths, support activities, preservation [4].

\subsection{Definisi Open Space}

Open space is a space formed by limiting nature by giving certain frames or restrictions [5]. Whereas in the Open Space 1 book, open space is a space that occurs by limiting nature to only two parts, namely in the field of the base and walls, whereas for infinite roof boundaries, more definition of open space can be interpreted as a man-made environment by having the intent and purpose certain and as part of nature [6]. Open spaces include:

- Open space is a container that can accommodate certain activities of the community either individually or in groups [7], in addition open space is a space consisting of hard space which is limited by architectural walls and used for social activities and soft space is dominated by natural environments such as gardens, green lanes and parks [8].

- Public space is a common property space and is a place for the city to carry out social activities that serve and also influence the lives of the city community. Public space is also a container of functional activities and activities in the city that can be done by a group of people and individuals in daily life and in periodic activities [9].

Some supporting aspects that exist in the open space are decomposed from the theory of the elements forming city space, namely the green belt, infrastructure including roads and pedestrian way of electricity networks, waste rubbish networks, public transportation, parking systems, crossing systems and street furniture.

\subsection{Smart City}

Smart City is a concept of developing, implementing, and implementing technology applied in an area as a complex interaction between various systems in it [10]. Smart City in the city sphere is essentially a Cyber-Physical-Social system, which is a system that is able to integrate the city's physical system, social system, and digital system through cyber (internet). The physical system of the city encompasses various life-supporting facilities and infrastructure in the form of urban infrastructure, while the city's social system includes various city governments, urban community groups, markets, urban communities and individual communities. Whereas digital city systems include computer network sensors, computing, and control [11].

The Smart City approach is divided into various sections, this division is carried out by IBM as the company that pioneers the establishment of Smart City, the division includes smart economy, smart mobility, smart governance, smart people, smart living, and smart environment. [12].

1. Smart economy, is the support of the city in managing a computerized economy so that services will be better. In the smart economy there are two dimensions, namely: the process of innovation and the ability of competitiveness.

2. Smart People, in this section there are criteria for the creativity process in humans and social capital. The following evaluation criteria are as follows:

a. The existence of formal education levels in the form of schools and colleges that is evenly distributed to the community and based on IT such as the application of e-learning, utilization of computer-based learning information systems

b. The existence of the IT community and other communities relating to the use of information technology.

c. The role of the community in the use of information technology.

3. Smart Governance, is a part specializing in governance. Cooperation between the government and the community is expected to bring about governance and a clean, honest, fair, and democratic governance, and better quality and quantity of public services. 
4. Smart mobility, is a part or dimension of Smart City that specializes in transportation and community mobility or more broadly namely the infrastructure and service systems in the city. In this smart mobility there is a process of transportation and smart mobility, so that public services are expected to be created for better transportation and mobility and to eliminate common problems in transportation, such as traffic jams, traffic violations, pollution and others .

5. Smart Environment, is a part or dimension of Smart City that specializes in creating a smart environment. The assessment criteria here include a process of sustainability and better management of resources. Smart environment is applied in a city encompassing: environmental protection, rubbish and waste management, energy management.

6. Smart Living, in this concept there are requirements and criteria as well as objectives for a better and smarter quality of life and culture management process. There are three categories that must be met in realizing smart living, namely:

a. Adequate facilities for the public by utilizing information technology such as providing free and healthy internet facilities (free from pornographic content, violence, through filtering / proxy systems), CCTV installed in public places and traffic to reduce the amount of crime.

b. Provision of city facilities and infrastructure that are safe and improve the quality of urban communities, and the provision of information related to the potential of local tourism well and attractively utilizing information technology such as the existence of a geographical information system for mapping the location of attractions, the process of booking tickets and hotel rooms online and mobile.

c. Adequate information technology infrastructure, so that all public facilities and services can run well through the help of computerization and information technology such as availability.

\subsection{Conclusion}

This study focuses on the open space of the city center as a support for the development of a city, based on the elements that form the city there are several aspects of the open space that will be arranged namely open space that includes (street furniture, green belts, utilization of the potential of open space as an energy source, and waste management in open space), infrastructure in the form of parking and circulation, markers, pedestrian paths, coupled with crossings, transportation syst ems, energy utilization and waste management, with a problem solving approach applying the concept of smart mobility, smart living and smart environment.

\section{METHODS}

\subsection{Research Method}

In this research the authors used a descriptive type of research with qualitative methods, that in simple descriptive research aims to make a systematic, factual, and accurate description of the facts and properties of a particular region [13], while the qualitative method, a method that involves interpretation and naturalistic approach, understanding and interpreting phen omena, and involving empirical materials [14].

In this research the data were taken using field observation techniques related to the physical aspects of open space, a literature study of the physical aspects and the concept of smart city, surveys of institutions related to local regulations and interviews with the community and city center stakeholders.

This research uses the character appraisal analysis technique to analyze the physical aspects of open space where this technique identifies a typical development pattern that illustrates a regional situation. This is used to identify the authen tication of the shape and character of the region [15]. The Character Appraisal technique can also measure the value of an area to a city by considering four measures of the quality of urban space namely: security and comfort, identity, use of elements, and maintena nce [16].

\subsection{Design Methods}

Designing a city requires decision making through a clear sequence or stage [17]. The sequence or stages are used to fulfill the purpose of designing the city. The following stages of research in designing a city:

- Analysis : Collecting and reviewing research object data

- Synthesis : Formulation of ideas and appropriate solutions

- Appraisal : Reevaluate by criticizing ideas or proposed setup criteria

- Decision : Formulation of the design concept

\section{DISCUSSION AND RESULT}

This stage begins with an explanation of the scope of the research area and then a discussion of the analysis of the open space of the Lamongan City center. 


\subsection{Scope of the Research Area}

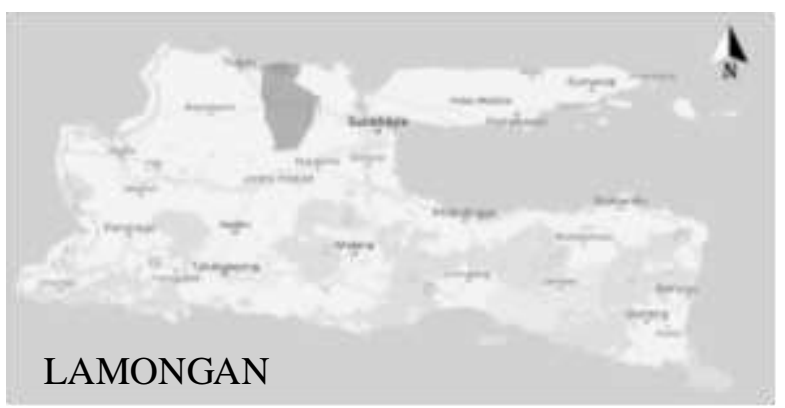

Figure 1.1 Scope of the Research

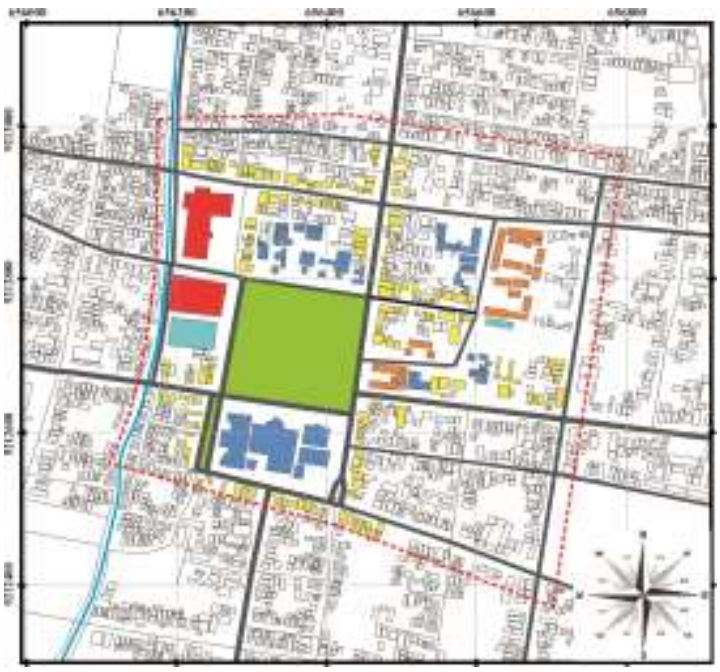

\begin{tabular}{|c|c|}
\hline Legend \\
\hline & Green Open Space \\
\hline & Government Buildings \\
\hline & Religious Buildings \\
\hline & Building Trades \\
\hline & Shop Buildings \\
\hline & Education Buildings \\
\hline
\end{tabular}

Figure 1.2 Map of the Research Area and Land Allocation in the City Center

Based on the map, the research area has various important buildings and land designations as the downtown area, so that the downtown area has very dense accessibility and activities due to the presence of these buildings.

\subsection{Public Transportation and Road Networks}

The central road of Lamongan City itself is included in the primary local road with two-way circulation, planned speed of $20 \mathrm{~km} / \mathrm{h}$, minimum road width of 7.5 meter and is well connected between each road. On the central road of Lamongan City, it can only be accessed by private vehicles, namely cars, motorcycles, bicycles, pedicabs, and motorized pedicabs, while trucks and other large vehicles are crossed across, but with the approval of permission from the local government.
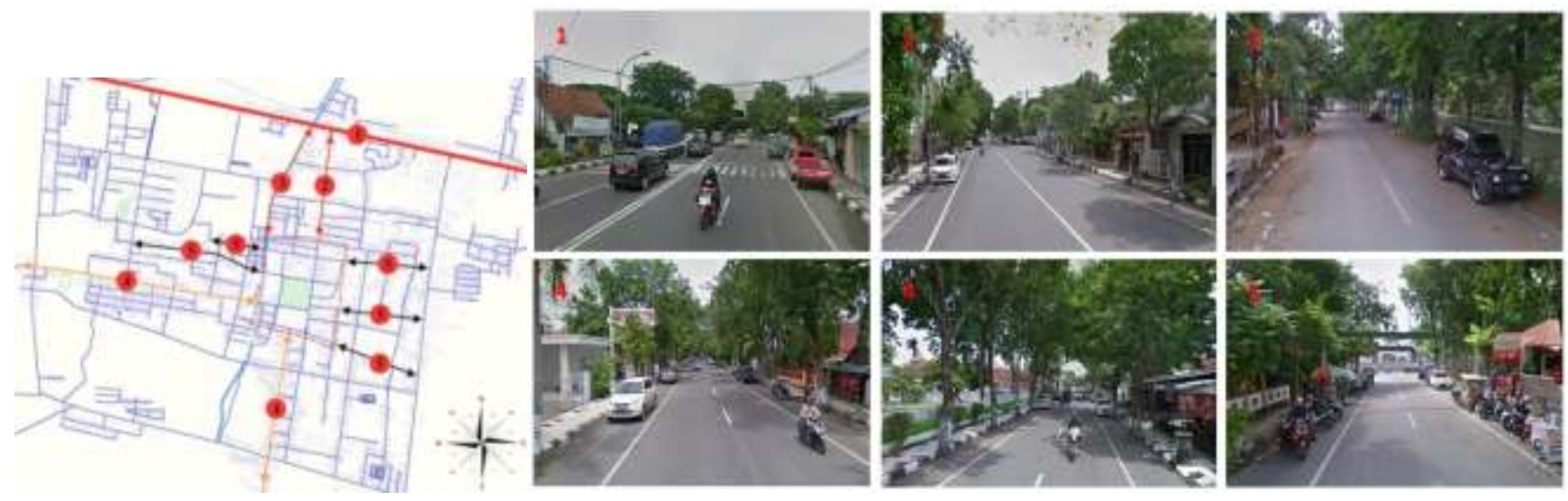

\begin{tabular}{|l|l|}
\hline Legend \\
\hline $1 \longleftrightarrow$ & City Provincial Road \\
\hline $2 \longleftrightarrow$ & City Primary Road \\
\hline $3 \longleftrightarrow$ & City Secondary Road \\
\hline $4 \longleftrightarrow$ & City Primary Road \\
\hline $5 \longleftrightarrow$ & Settlement Road \\
\hline$\longmapsto$ & Street Structure of Lamongan Sub-district \\
\hline
\end{tabular}

Figure 1.3 Lamongan City Road Structure 
In the center of Lamongan City, it is dominated by two-wheeled and four-wheeled private vehicles, with public vehicles only in the form of pedicabs rickshaws and motorized pedicabs which are usually called BELA (Becak Lamongan/Lamongan pedicabs).

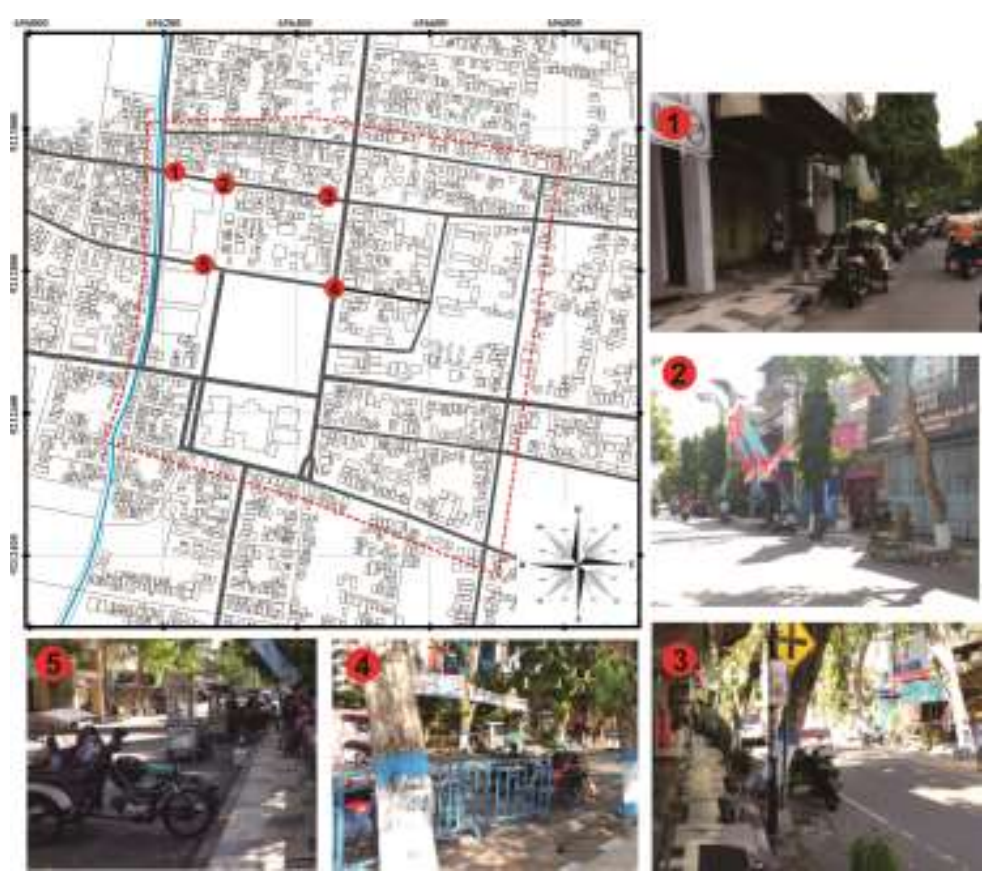

Figure 1.4 The Condition of Pedicab Transportation Base in Lamongan City Center

\section{Analysis}

Comfort and Safety: From the physical comfort and safety of the road infrastructure, it is quite comfortable with good road quality with a smooth asphalt cover material so that it does not cause shocks when driving, the main road has an average width of $13 \mathrm{~m}$ which can be used for vehicle access, but in terms of functional and visual Lamongan City center road is still not comfortable and safe because of illegal parking and street vendors that cause traffic jams. The level of comfort of the city center in terms of the transportation network system can be said to be lacking, this is due to the absence of vehicles that are according to standards and have a sufficient level of capacity for the visitors even though it has been supported by good road conditions

Identity: : Roads in the city center already show identity as the city's primary roads with physical conditions and dimensions, but they still do not reflect the downtown area because it has the same closing elements as areas outside the city center. Whereas the existing transportation is in the form of pedicabs with designs in general, the identity that distinguishes from other pedicabs is only on the specific mention of BELA (Becak Lamongan /Pedicab of Lamongan), while from the road factor, the city center still does not have differences in the identity of the road between thr city center and the surrounding area.

Use of element: In terms of road maintenance, the road is quite good with no potholes and damaged roads, while for public transportation maintenance there is still not good with the non-standard of some existing rickshaws, rickshaws modified by motorbikes, and no base provided for rickshaws.

Maintenance: : In terms of road maintenance, the road is quite good with no potholes and damaged roads, while for public transportation maintenance there is still not good with the non-standard of some existing rickshaws, rickshaws modified by motorbikes, and No. base provided for rickhaws

Analysis Conclusion: Based on the discussion above, it can be concluded that the condition of the roads in the center of Lamongan City has been very good in terms of physical quality in the absence of damaged roads, but there has been a decline in the quality of functions due to inaccurate function of the road as a street vendor area and vehicle parking. The quality of transportation in the open space is dominated by private vehicles, while public transportation is only in the form of pedicabs with limited capacity and does not comply with transportation standards, nor is there a clear area for public transportation, so many pedicabs stop at certain areas that are not special areas, this causes a decrease in the visual quality of the city with irre gular pedicabs, as well as a number of pedicabs that stop interfering with the vehicle's circulation path, this is very inconsistent with the concept of smart mobility, which requires that movement in a space must not be impeded by other elements

\subsection{Pedestrian way}

The pedestrian way network in the center of Lamongan City is spread on the right and left side of the road and surrounds the town square, the pedestrian way structure in the center of Lamongan City is shown in the following figure. 

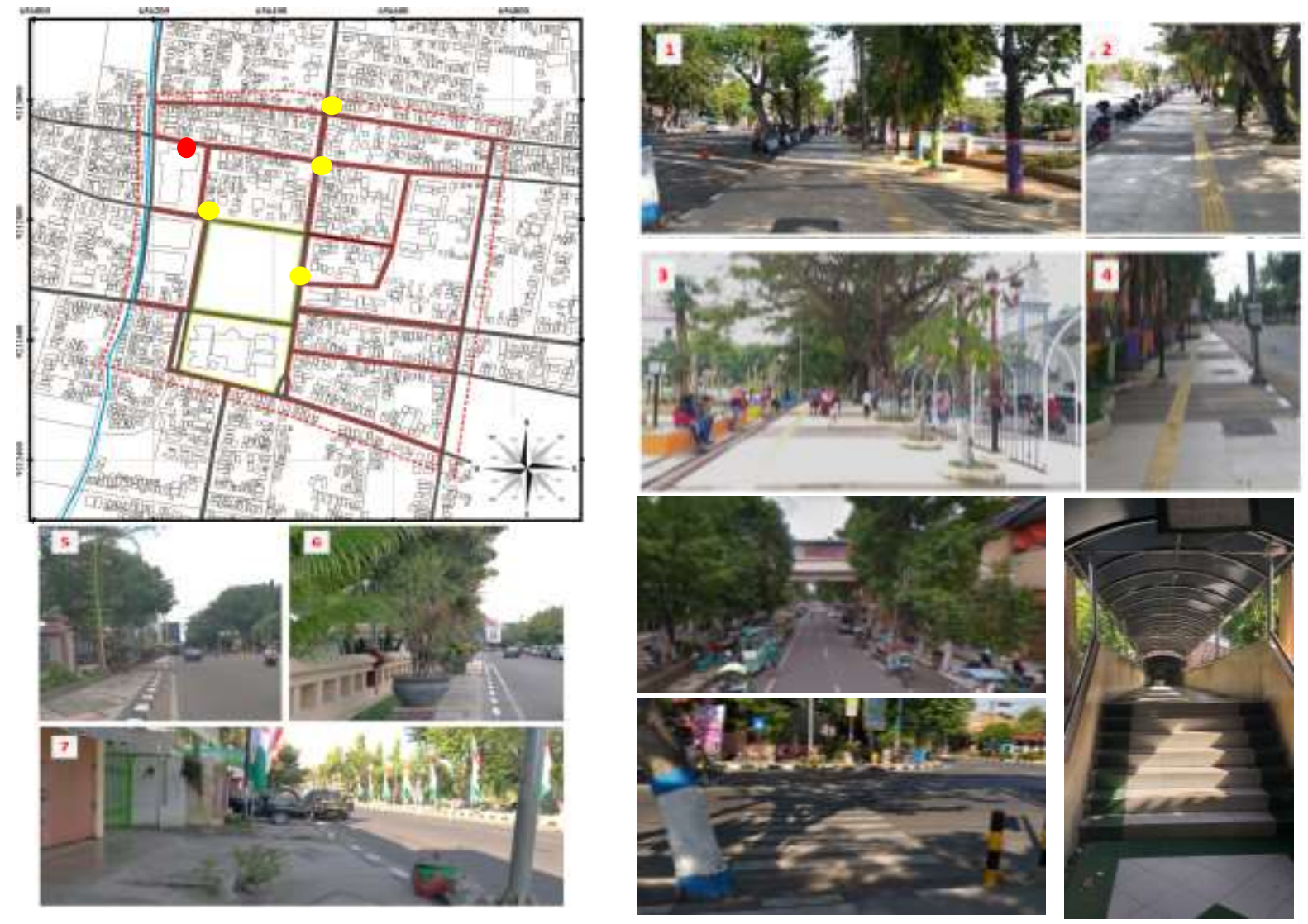

\begin{tabular}{|c|l|}
\hline Legend \\
\hline & Pedestrian way square tackle material with a width of at least $2 \mathrm{~m}$ \\
\hline & Pedestrian way material with gravel patterned with a minimum width of $1 \mathrm{~m}$ \\
\hline & Pedestrian way patterned tackle material with a minimum width of $1 \mathrm{~m}$ \\
\hline & Bridge crossing \\
\hline & Zebra crossing \\
\hline
\end{tabular}

Figure 1.5 Structure of Pedestrian Way Type in Outer Space of Lamongan City Center

\section{Analysis}

Comfort and Safety: The level of comfort in the pedestrian is still lacking with damage to some cover elements, as well as obstruction of some lanes by the placement of street furniture, street vendors, and motorcycle parking that is not quite right and the disability lane is not connected, in terms of pedestrian way security is not good enough with several broken pedestrian by the village road as well as several width pedestrian lines that are not wide enough for people to pass and can reduce the functional quality of the pedestrian, and the crossing paths do not have a security system.

Identity: The pedestrian way in the city center does not have a strong identity as an urban infrastructure that is functioned by pedestrians because most of the pedestrian way is misused as a parking area and also a street vendor area, and the pedestrian closing elements still do not have a harmony of colors and patterns so that it cannot shows the unity of space. The crossing system still cannot show the identity of the city center, because it has quite poor quality.

Use of element: The pedestrian way has used natural material in the form of gravel on some pedestrian which has a width of 1 meter while on the pedestrian way with a width of 2 meters using a cover material in the form of beige tackles, crossing line $\mathrm{s}$ using white paint and directly painted on the asphalt surface.

Maintenance: In terms of maintenance, some pedestrian ways are not in good condition and there are traces of dirt that are not cleaned and have an impact on deteriorating visual quality, while maintenance on the crossing path is very bad with the fadin gof paint on zebra cross

Analysis Conclusion: Based on the discussion above, it can be concluded that the conditions of the pedestrian way in the open space of the Lamongan City center are not well connected in terms of the width of the pedestrian way that is different for each road lane, disability facilities that are not well connected, or the pedestrian way floor covering elements that do not have the impression of one the unity of the downtown area, and there are some elements of pedestrian floor coverings that are damaged and dirty, this is due to poor maintenance of the pedestrian pathway which causes the city community's lack of interest to carry out walking activities in the open space of the Lamongan city center, thereby causing community dependence on vehicles that can 
increase pollution and congestion, in addition to the absence of a security system on the crossing lane have an impact on the decline in urban society to cross the lane that has been provided.

\subsection{Parking Area}

Based on field observations, that in the open space of the center of Lamongan City there are public parking facilities namely on the outside of the Lamongan level market building and on the Jami' Lamongan mosque section, as well as on street parking.

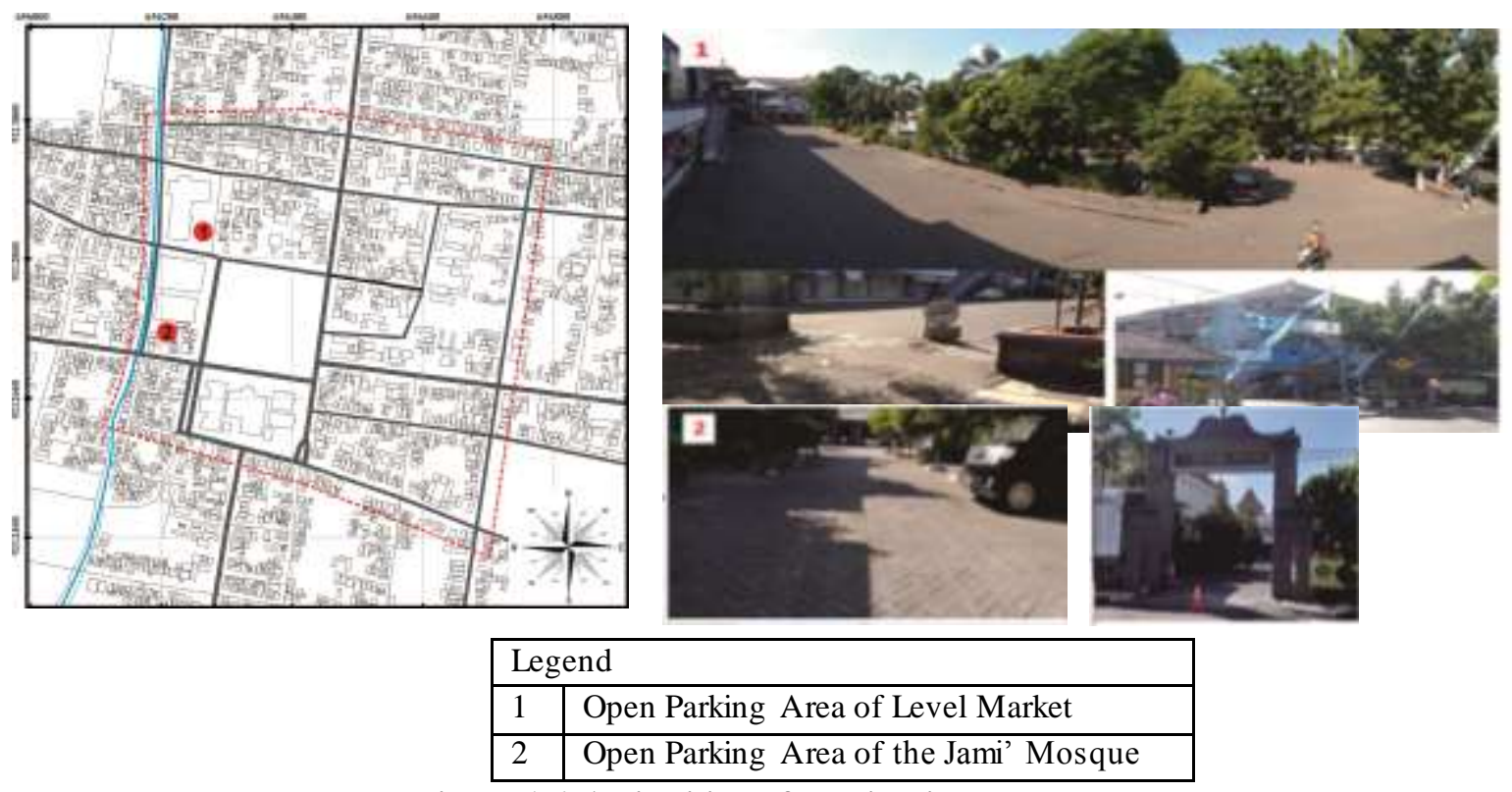

Figure 1.6 Availability of parking in downtown Lamongan

\section{Analysis}

Comfort and Safety: The parking system in the open space of the Lamongan City center based on the data above is not able to provide a sense of security and comfort. This is caused by several factors, namely the lack of land for parking areas, existing parking facilities that are not supported by security systems, as well as the number of parking areas that do not fit the purpose, as in the pedestrian way and on the road, as well as the lack of good city government policy on the parking system, this can be proven by the existence of on-line parking facilities on several sides of the town square that have parking angles that are not parallel to the shoulder of the road, and causing a reduction in the body of the road for the movement of the vehicle this ca uses disruption of vehicle circulation and also affects the decline in the level of security along the vehicle lane.

Identity: In terms of identity, the existing parking system does not yet show the parking system of a city center that should be well-organized and well-planned parking lot so that it does not cause problems in the downtown mobility system that has high mobility.

Use of element: Existing parking facilities in the open space of Lamongan City center use floor coverings in the form of paving without a pattern with new borders in the form of trees in the level market area or mosque, while on-street parking utilizes asphalt elements of the highway.

Maintenance: In terms of maintenance the parking conditions in the area of the mosque of Java are very clean without any trash or damaged elements, while at the level market there are some garbage scattered in the parking area and some broken pavement elements.

Analysis Conclusion: Based on the discussion above it can be concluded that the parking area in the open space of the city center is limited to the Jami' mosque and market level, but the parking area is still not sufficient to accommodate public vehicles, so that the number of illegal parking in the city center, especially on the pedestrian way and road bodies which cause a decrease in the level of quality of the space in the city center in terms of both visual and functional, because it triggers other problems such as dis ruption of motor vehicle circulation while moving or disrupted pedestrians who move to move using the pedestrian way.

\subsection{Street Furniture}

Street furniture that can be found in the open space of downtown Lamongan namely: street / park benches, billboards, street / park lights, and signage.

- $\quad$ Street / park benches are only found on town squares with many damaged street / park benches. 


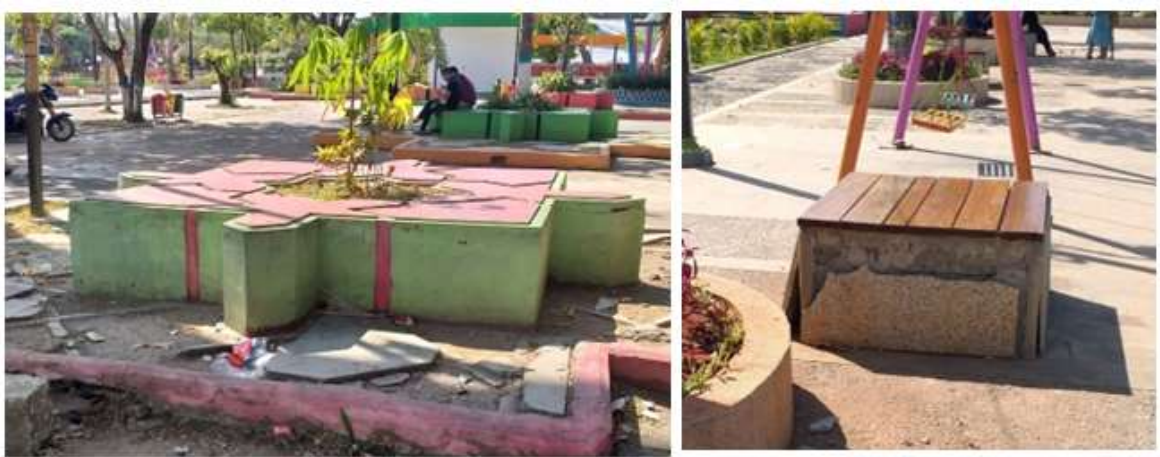

Figure 1.7 Park Bench

- Billboards in the open space of Lamongan city center are located at the crossroads, but there are some illegal billboards attached to electricity poles and trees.
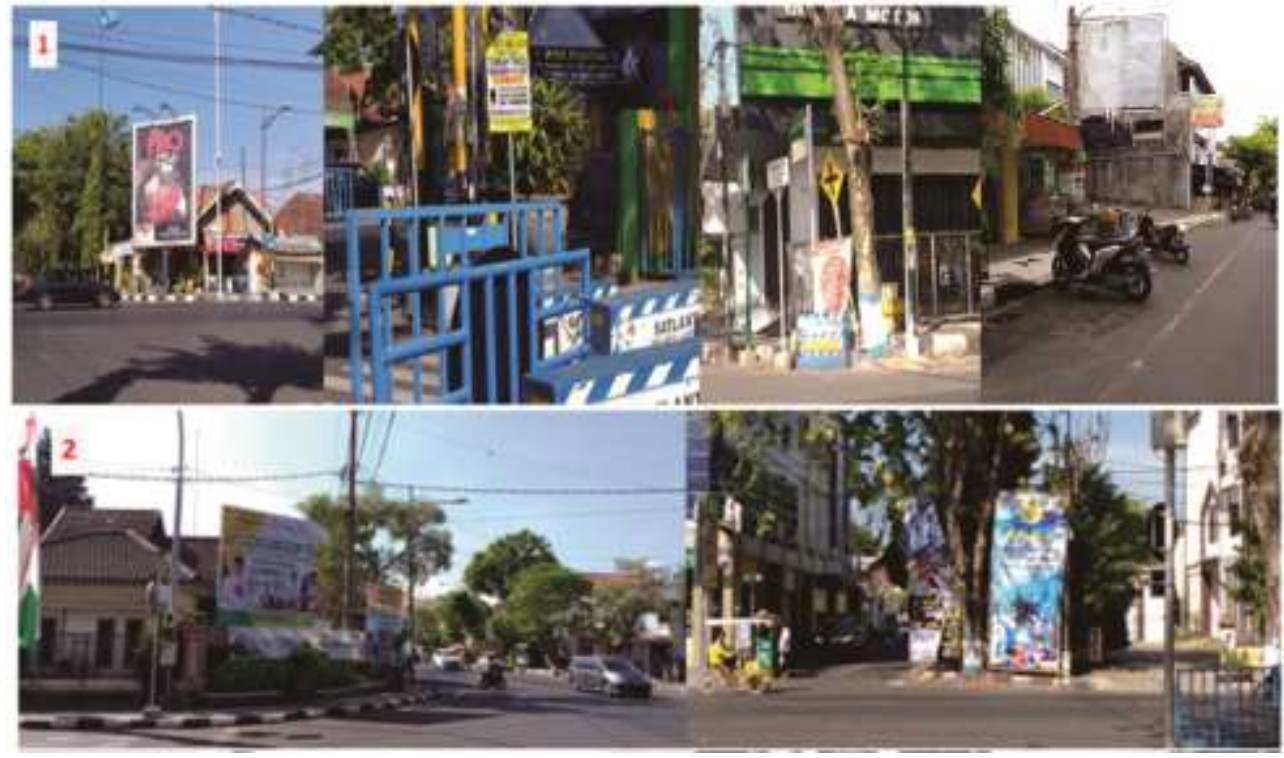

Figure 1.8 Condition of Billboards in Outside Space in the City Center

- $\quad$ Street / garden lights spread well in open spaces but have poor lighting quality

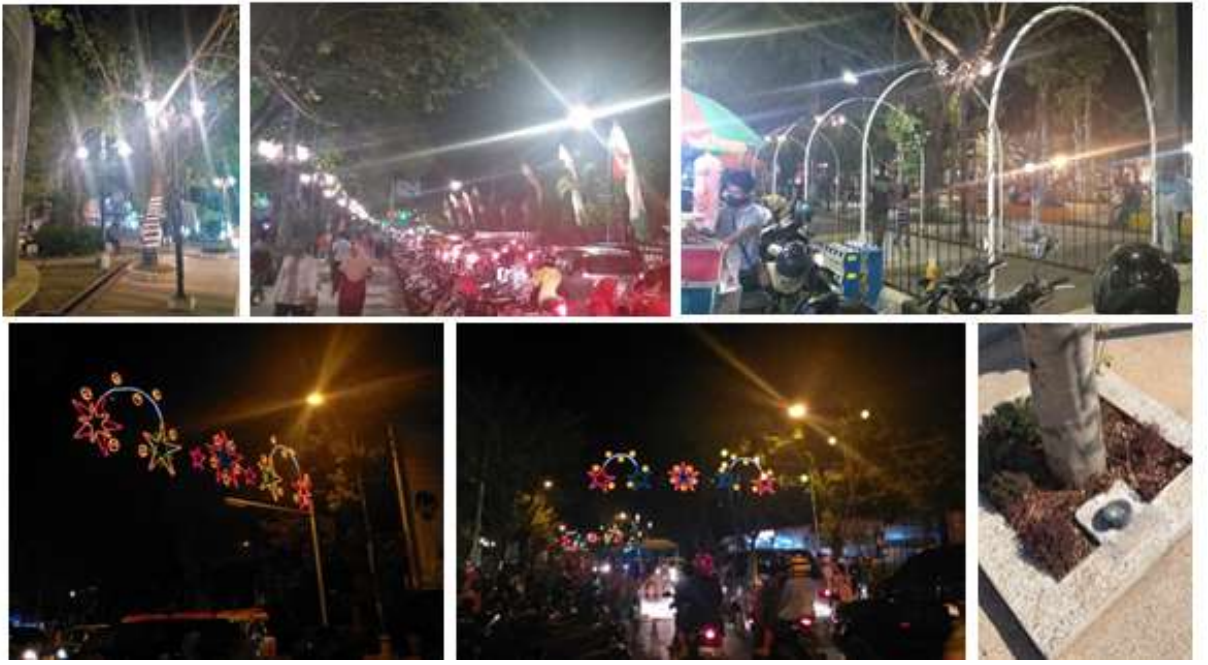

Figure 1.9 Street / Park Lights

- Based on field observations, that the center of Lamongan City has 8 city signage, five of which are located in the town square in the form of three fountains, water tower, and signage in the form of a plane in the middle of the square, while outside the square area namely the statue of the catfish milkfish monument and horse statue. 


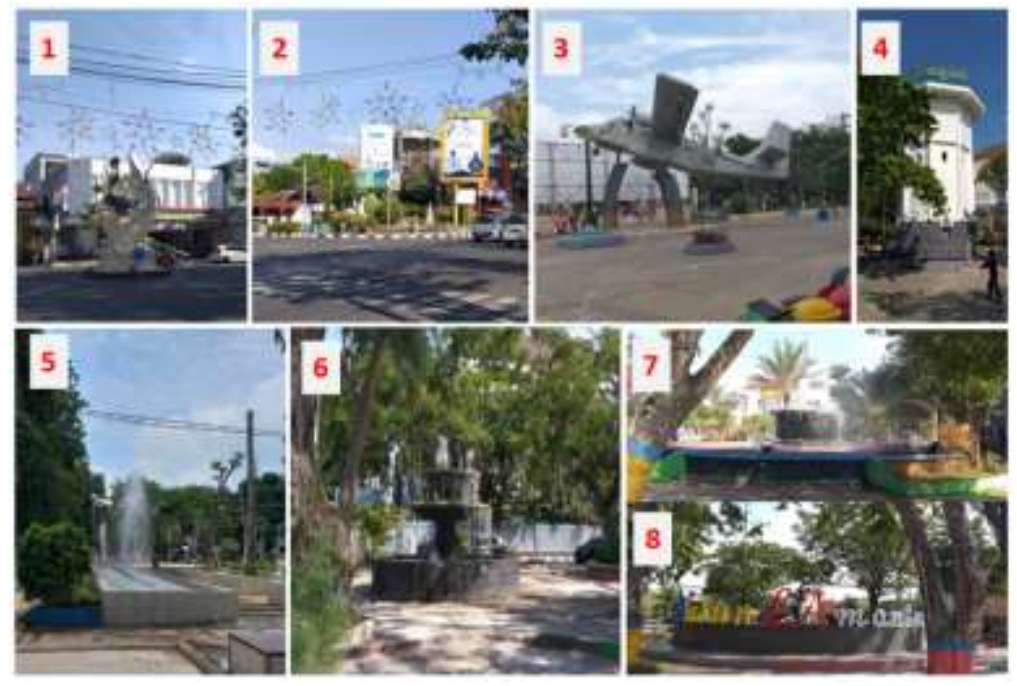

Figure 1.10 Types of Sigange in the Outer Space of Lamongan City Center

Analysis

Comfort and Safety: Some Street furniture in open space of the city center is obstructed by other elements, such as billboards that are blocked by trees so that the function of billboards is not optimal, other than that the condition of street furniture is not in good condition with the number of park benches damaged, the lighting quality is not good, the fading picture of billboard, and fountain signage is not facilitated by a guardrail, this will be very worrying for parents who bring children to move around the fountain.

Identity: Street furniture material is dominated by concrete and iron, while natural elements are in the form of wood as a layer of park benches and water elements found in city signage.

Use of element: In terms of identity, street furniture is still not able to show the character of Lamongan City in general, and the character of the city center in particular, this can be seen from some street furniture that does not reflect the identity of the city, besides that street furniture does not have a special character compared to other regions.

Maintenance: In terms of care for street furniture is very bad, this can be seen from some of the paint on the street furniture fading and peeling, the water condition on the signage is very dirty and mixed with leaf litter, and the fading of advertise ment boards

Analysis Conclusion: Based on the discussion above, it can be concluded that street furniture in the open space of the center of Lamongan City still does not have a good condition so that the role of street furniture has not been able to support community activities and cannot support the realization of the concept of smart living in open space in the center of Lamongan City.

\subsection{Green belt}
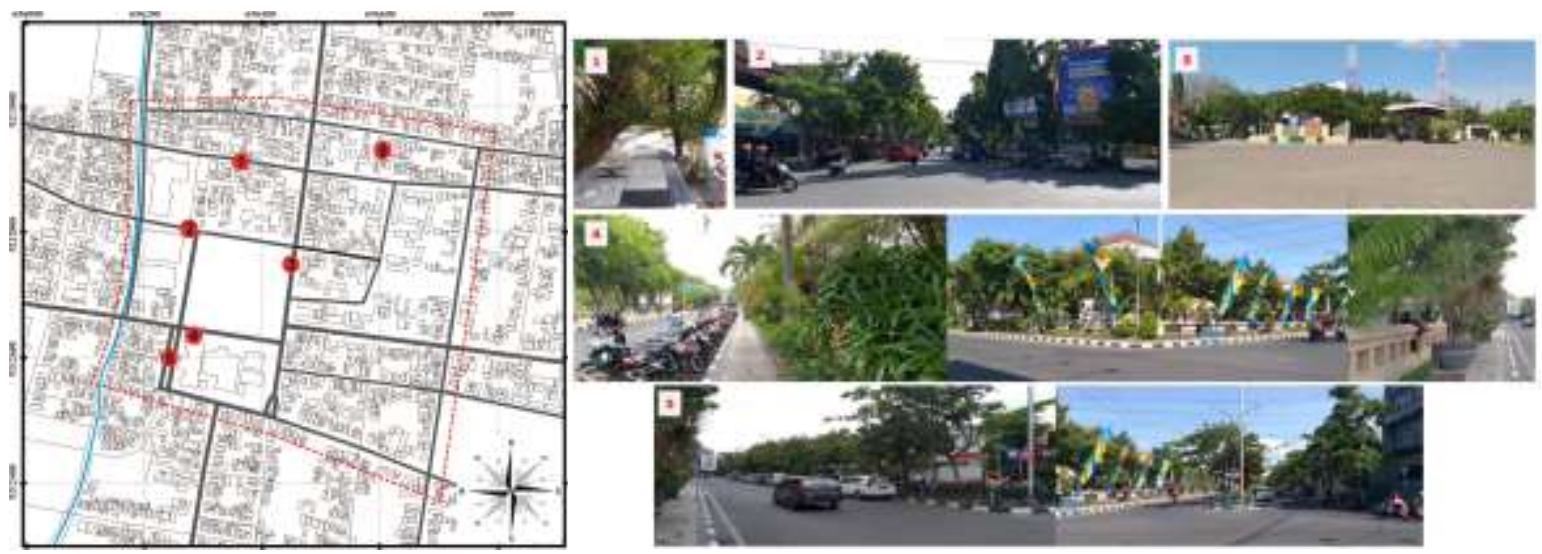

Figure 1.10 Types of Signage on outer space of Lamongan city center

The Green Belt in the open space of the city center is quite well spread out, in each of the road and pedestrian lanes, especially in the town square. Green belt in the open space of Lamongan City center in the form of shady trees, ornamental plants, and green open spaces found in the Lamongan City square. 


\section{Analysis}

Comfort and Safety: In terms of comfort the green belt which is dominated by shady trees is good enough to overshadow the pedestrian way but the lack of spreading of trees and the absence of ornamental plants that can provide visual comfort to the city space especially along the pedestrian way, on the town square the green belt is spread around town square but in the city ce nter there are still some sitting areas not shaded by trees, while in terms of security the trees that grow on the pedestrian path are very dangerous for pedestrians and also cause a decline in the quality of comfort.

Identity: In terms of the meaning of space, the green belt has not been able to improve the impression of a city center space with the improper placement of tree dimensions and lack of vegetation that can be used as focal points in city space because it is dominated by shady vegetation in green and in open space in the city center of Lamongan the lack of vegetation brightly colored flowers that can improve the visual quality and meaning of the Lamongan City space and the lack of pollution-absorbing vegetation along the road.

Use of element: Green belt of the types of trees, flowers and grasses that grow naturally or are intentionally planted and do not rely on ornamental vegetation made of plastic or same kind of that.

Maintenance: In terms of care it is still not good enough with the trees that grow on the pedestrian way and some shady trees that are not pruned on the road, as well as flowering vegetation in wilted conditions and lack of care, especially in the pedestrian way area, while for the square area the newly planted flower plaza is still in wilted condition, this is also caused by the City of Lamongan which experiences a lot more dry season than in rainy season with temperatures of $26.4^{\circ}-28.4^{\circ}$ which causes the plants to wilt slightly and dry out.

Analysis Conclusion: Based on the discussion above that the Green Belt in the open space of the central city of Lamongan is dominated by shady trees and has little ornamental vegetation on the pedestrian way, ornamental vegetation is most commonly found on town squares but in still withered conditions and less varied flowering vegetation so not yet giving the impression of an open space that has good visual quality, whereas from functional lack of pollution-absorbing vegetation and lack of maintenance for existing vegetation.

\subsection{Energy Utilization}

Based on field observations on the open space of the Lamongan City center it was found that most of the facilities and infrastructure in the open space of the Lamongan City center use electricity and solar energy, but most of it is dominated by the use of electrical energy, along with pictures of the availability and conditions of energy use in the open space downtown Lamongan.
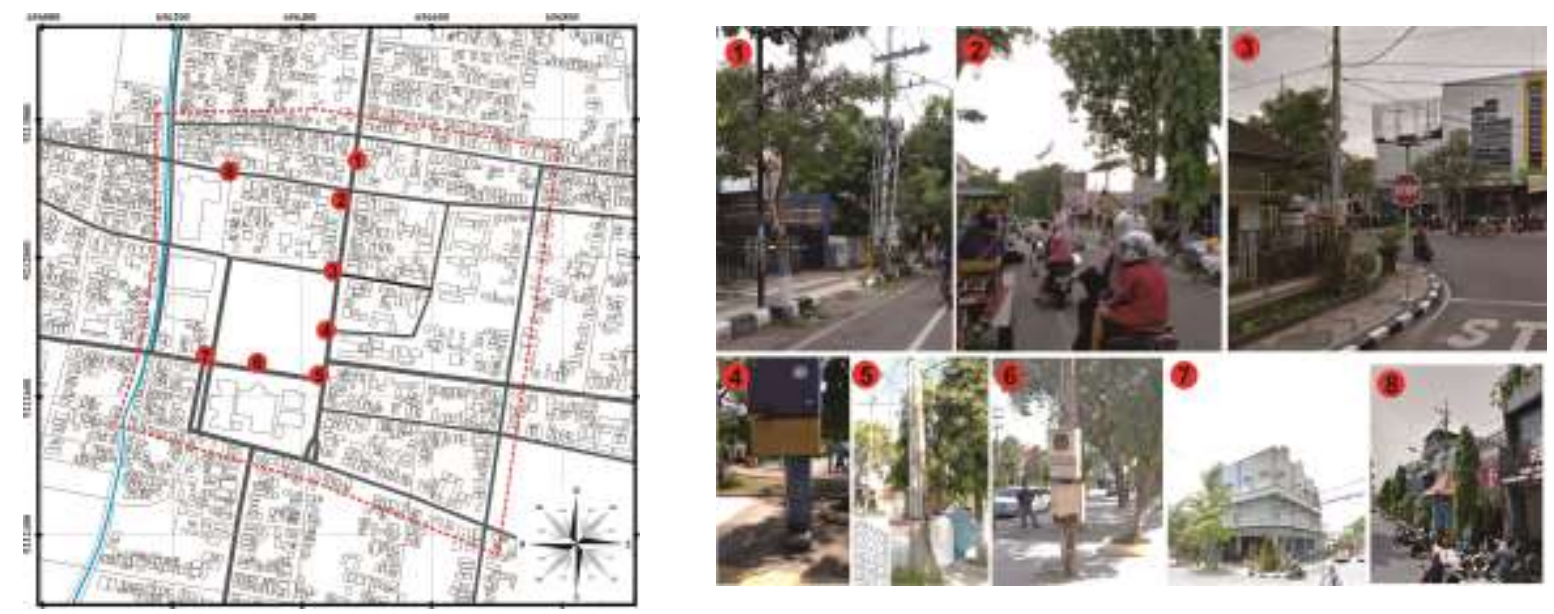

Figure 1.11 Energy Utilization in the Outer Space of Lamongan City Center

\section{Analysis}

Comfort and Safety: Some electrical cables that collide with trees are very dangerous when the tree grows twigs and will also be very dangerous when there are strong winds in the city center that cause cable friction with the tree trunk, but also some electrical boxes in poor condition without any safety locks and placement a box that everyone can reach. Meanwhile, in terms of the comfort of the existence of electrical wires that hang on the ceiling of city spaces where the placement is less tidy, it causes a decline in visual comfort in the city center.

Identity: The use of energy which is dominated by electrical energy rather than solar thermal energy has not shown the character of Lamongan City which has a longer dry season than rainy season and the heat temperature is above the average of the tropics ie $26.4^{\circ}-28.4^{\circ}$ even more during the long dry season.

Use of element: The use of solar thermal energy is still very limited even though it has considerable potential as the main energy for urban infrastructure and facilities that are supported by the climate and temperature conditions of the City Lamongan but now 
still relies on the use of electricity that is connected to the steam power center electricity which can contribute to pollution for the environment.

Maintenance: In terms of maintenance the solar panels have good conditions, while the cables and electrical boxes have unfavorable conditions, with some electrical control boxes not having a security system, the electrical boxes are in a rusty condition and the electricity cables are not tidy.

Analysis Conclusion: Based on the discussion above that the center of Lamongan City still relies on electrical energy sources with unfavorable conditions in its system, causing the suboptimal utilization of the natural potential of the Lamongan City center and some elements of the electrical system such as cables and electrical boxes in unfavorable conditions resulting in a decre ase in visual quality from the open space of the center of Lamongan City with a variety of cables that hang neatly.

\subsection{Waste Management}

In the center of Lamongan City, there are several limbic systems namely waste, drainage and clean water. The garbage system at the center of Lamongan City uses a garbage bin system which will then be transported to a temporary landfill (TPS) that is outside the downtown area, then the waste will be sent to a landfill (TPA) owned by Lamongan City. in the path of the building are important several types of trash cans are found but in poor condition, while in the town square has a trash bin that is quite diverse and in good condition.
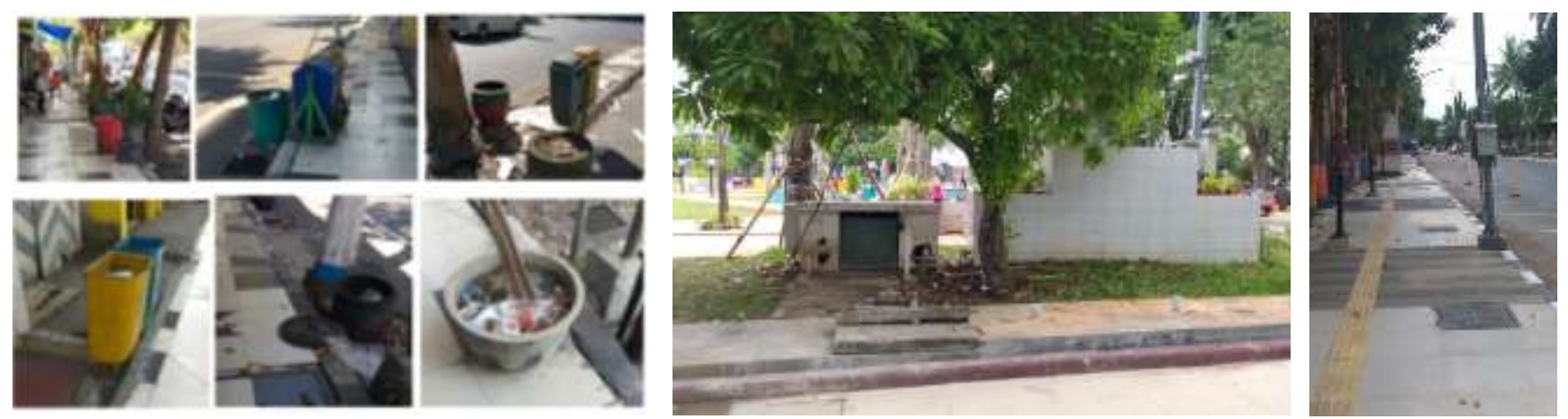

Figure 1.12 Waste Management in the Outer Space of the City Center

\section{Analysis}

Comfort and Safety: The condition of the sewage network in the open space is very alarming with the number of garbage bins having overloaded because many trash bins are damaged, so that there are many flower pots and water barrels to dispose of garbage, in addition to the lack of spreading garbage bins on the pedestrian way and the city center itself does not have a management center existing rubbish, besides that in the town square, the garbage bin is in a new condition, but the number of trash has lost its cover and the many types of garbage dumped are not in the appropriate type of garbage, whereas for water waste that is on the pedestrian path in conditions good, but when it rains, there are many stagnant water in the road area due to the uneven flow of water discharged into the river, while in the plaza the gutter flow is filled with organic and inorganic waste and water storage in the square often floods the area around the storage because water collection is overloaded.

Identity: In terms of identity, if viewed as a whole, it has not been shown that the city is clean and the management system of rubbish or water waste is bad, while in terms of the design of the trash has the same shape in general with the division of three types of waste.

Use of element: The state of waste at the center of Lamongan City is still unable to utilize the potential of the existing environment as a source of waste management

Maintenance: With the condition of several broken garbage bins, overloaded rubbish, scattered rubbish, the absence of waste management and waste water systems that are experiencing problems show a very poor level of maintenance.

Analysis Conclusion: Based on the discussion above, the Lamongan City Center has a poor level of waste and water treatment that can threaten the quality of the environment owned by the Lamongan City Center by overloading existing waste and waste water storage systems and waste management systems and water that is not good enough so that it can affect community activities as well as visitors to spaces outside the city center besides that conditions.

Based on the discussion above, the open space of Lamongan City Center requires several structuring criteria as follows:

1. Public transportation must be able to accommodate more passengers, and have a clear lap.

2. Roads in the city center must have their own character in terms of visual and material use to realize the unity of space in the city center and to have circulation and designation of road bodies that are easily known to the public. 
3. Must be safe and comfortable without being hindered by any element in supporting the movement of the community and can properly serve people with disabilities so that the existence of pedestrian way can help the realization of smart living.

4. The new structure of the parking system that does not interfere with visual quality and does not interfere with the function of other elements in the open space of Lamongan downtown.

5. The crossing lane must have a good security system and can regulate the tempo of the vehicle's speed to support a sense of comfort and safety when crossing.

6. Street benches / parks must be able to serve community activities and can create social harmony in the open space of the center of Lamongan City.

7. Street / park lights should be able to help improve the visual quality of the open space of Lamongan City center.

8. City signage must be able to show the character of the City of Lamongan and be able to improve the impression of space in the open space of Lamongan city center

9. Physically and material billboards must have a sustainable and friendly value and are resistant to environmental confition outside the center of Lamongan City.

10. Road signs, direction boards and road marking boards must be easily seen by the community and not disturbed or covered by other elements in the open space of Lamongan City Center.

11. In addition to decreasing temperature and pollution of vegetation must also be able to improve the impression of space and visuals from the open space of Lamongan downtown

12. Periodic control must be carried out so as not to obstruct the movement of rubbish waste and water waste management in the open space of Lamongan Downtown.

\subsection{Concept}

- Arrangement one-way circulation on the main road to widen the pedestrian way and public transport lanes so that the circulation of the community and vehicles remains smooth.
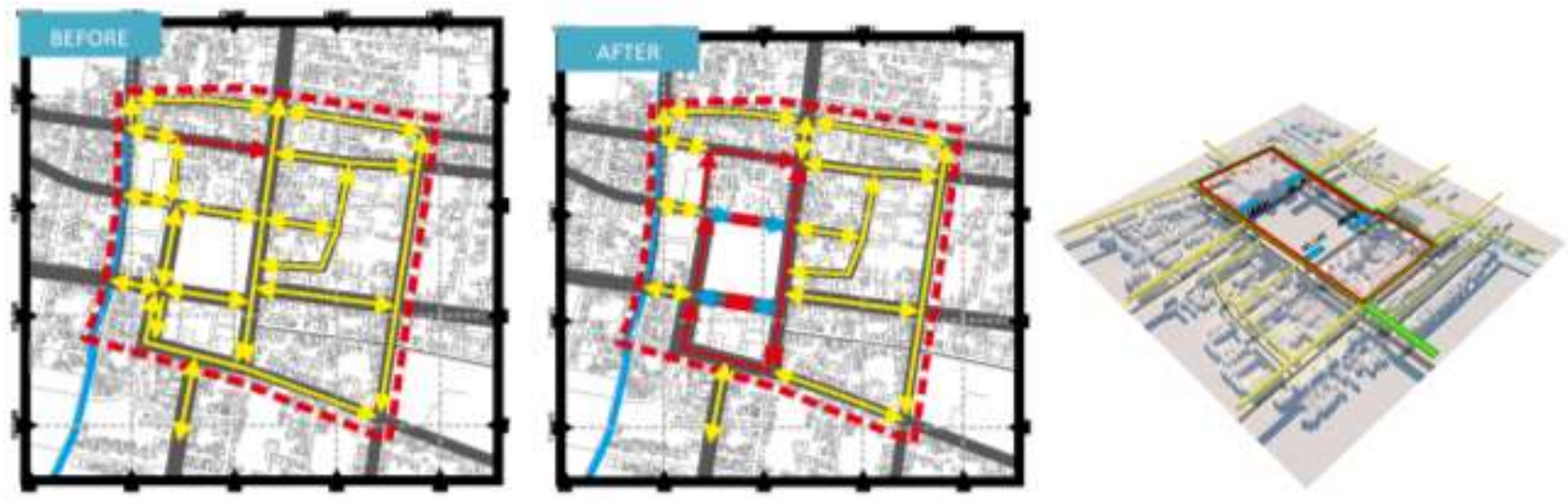

The regulation of vehicle circulation, especially on the main lane of the city center, is one-way, the purpose of the one-way circulation regulation is to utilize part of the body of the road to widen the pedestrian way. The red lane shows the main lane with one direction to the right and left of the road is an important building and figure, while for the yellow color is a two-way lane that is in the residential area of citizens, for the green color shows the circulation path of public transport while the blue color is the road intended to enter and exit the parking area.

- $\quad$ Reduction of private vehicles by adding solar-powered public transportation facilities and using rickshaws that are more environmentally friendly.
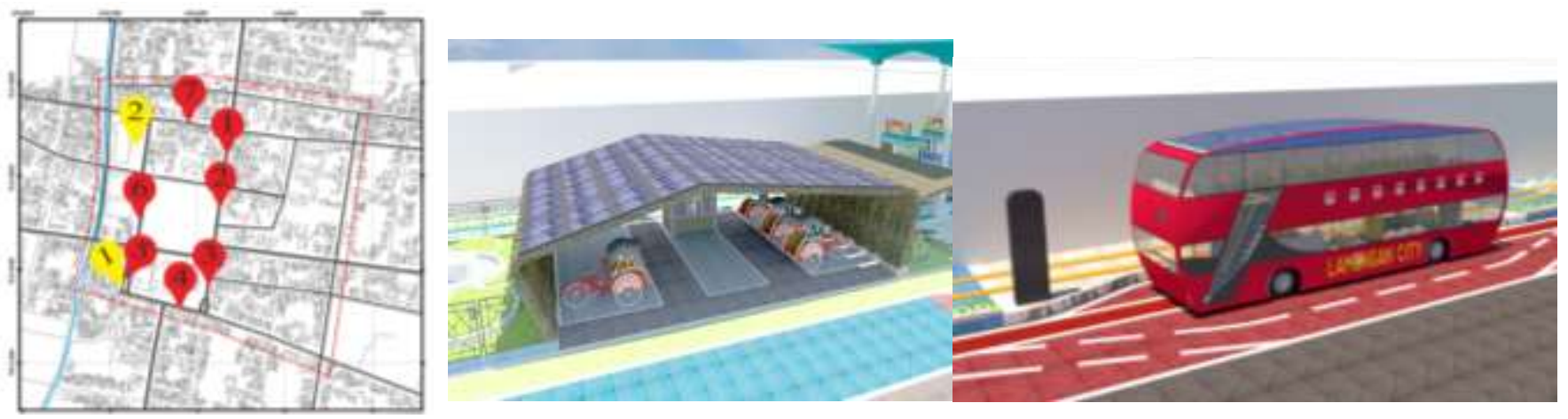
The use of rickshaws as public transportation that at any time can help mobility in the open space of the city center remains smooth by not harming the surrounding community, because many surrounding communities make the rickshaw as a main job, besides rickshaws are also more environmentally friendly without causing pollution. rickshaws are located around government buildings that are designated number 1 in yellow and the market is designated number 2 in yellow, the existing pedicab base is connected to a communication system equipped with IoT (Internet of Thing), so that the downtown community can at any time access and order rickshaws to move in the downtown space or transport goods in the open space of Lamongan downtown.

- Concentrate the parking area in one place, with the basement system in the town square of Lamongan .

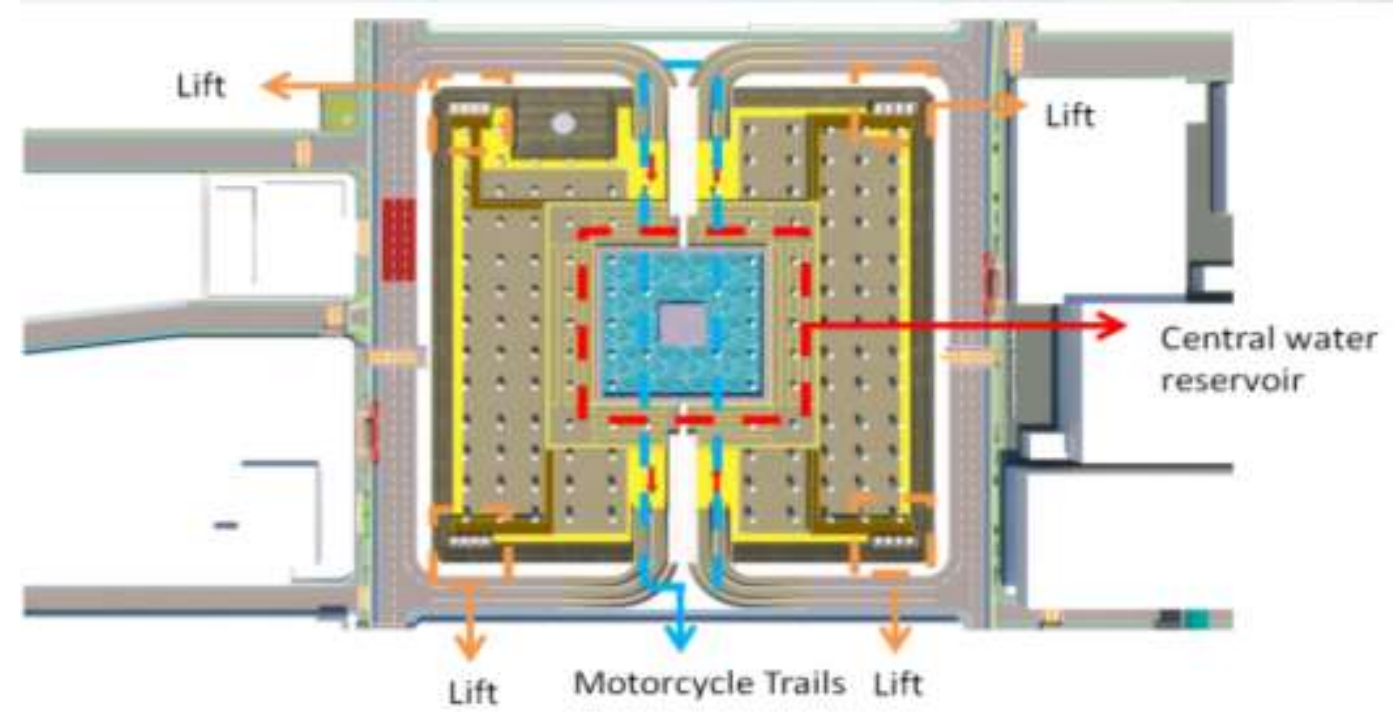

- Distribution of vehicle lanes is namely private vehicle lanes, public vehicles and bicycles, so as not to interfere with each other between vehicles.

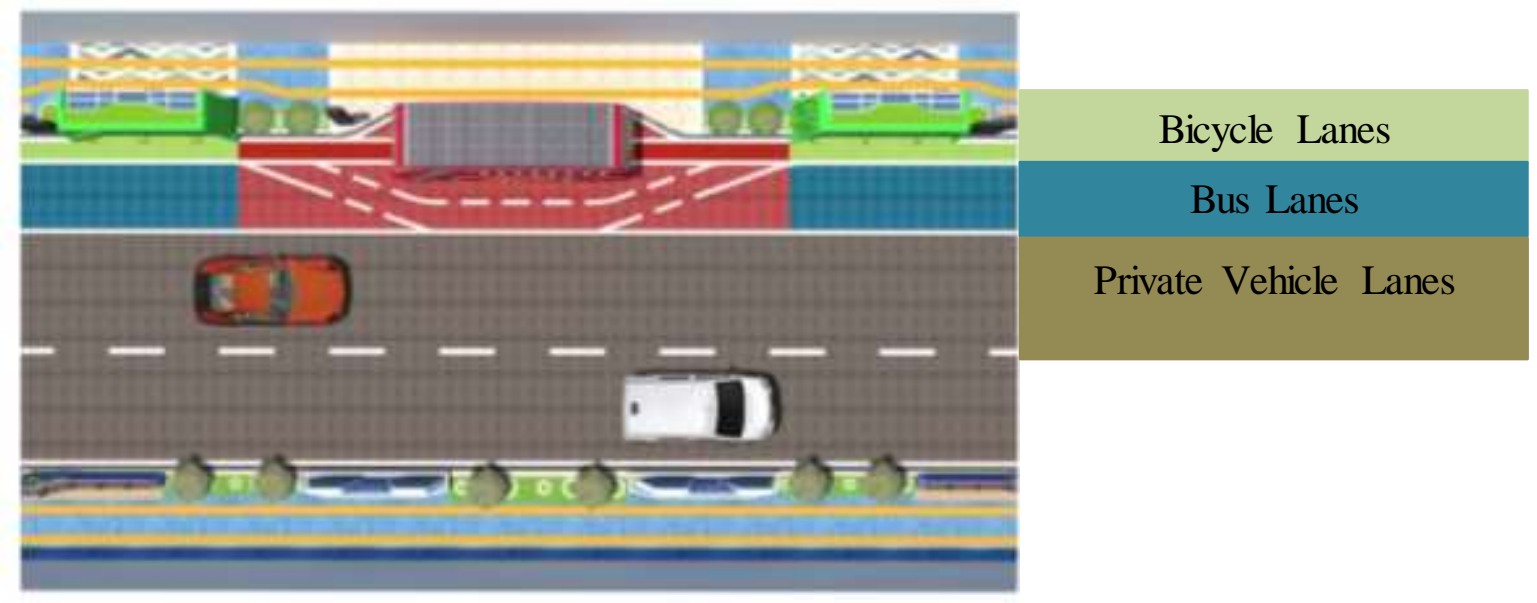

The red color in the picture shows the special area of the bus to lower and raise passengers in the open space of the city center, when the bus stops the bicycle lane will be needed in the direction of the bus lane so that the movement of the cyclists is not disturbed by the bus that stops 


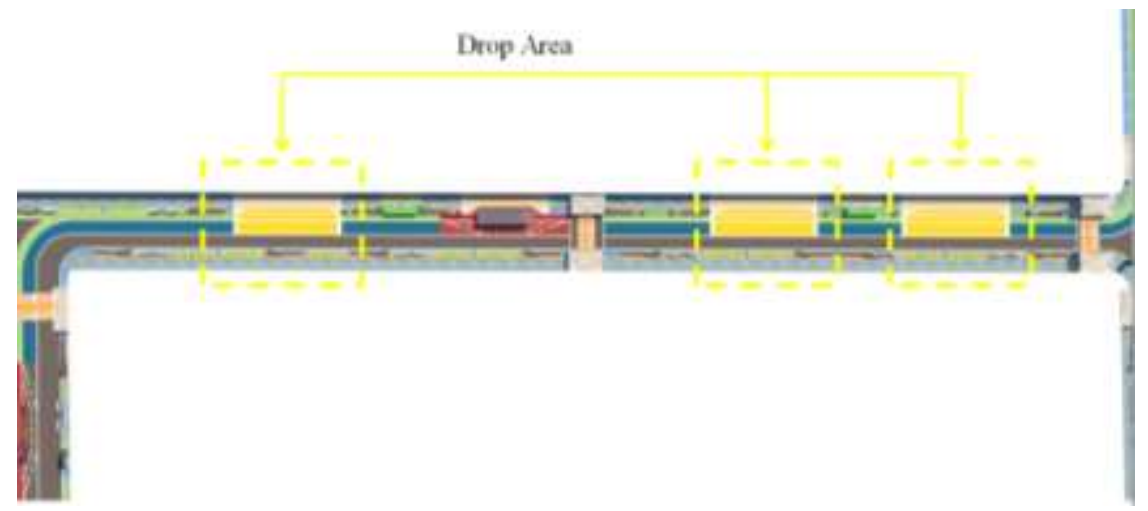

In the shopping area a special area is facilitated for lowering vehicles and transporting goods, so that economic mobility remains smooth.

- Provide bicycle parking area in open space of Lamongan City center

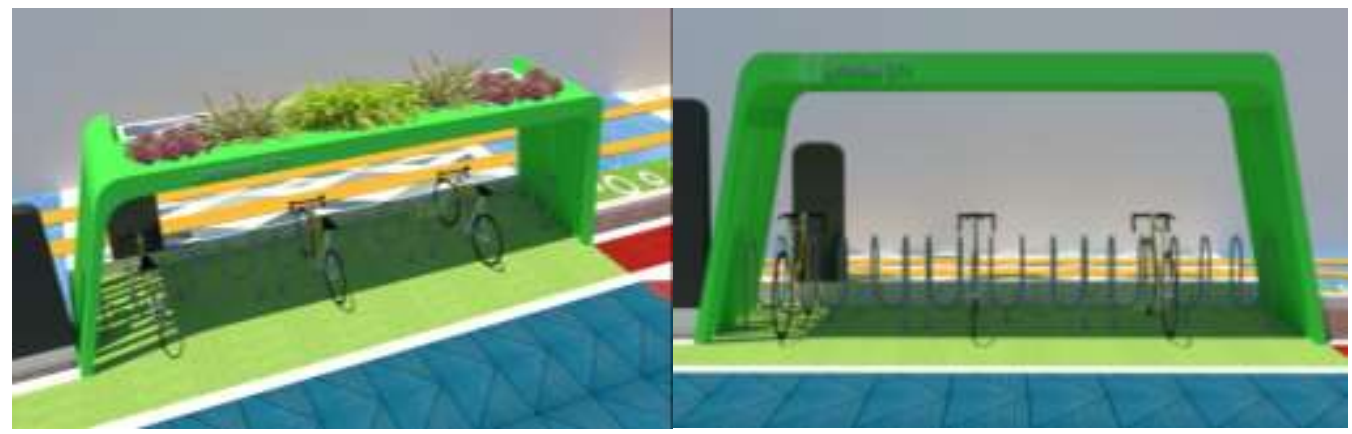

Bicycle parking with E-Card Parking system provided, so that bicycle security will be guaranteed, besides that bicycle parking is provided free of charge and different from motorized vehicles that are charged, the policy aims to make people not dependent on public vehicles so that the environment and quality of life of the central community the city will be awake. The bicycle parking lot is also equipped with solar panels as energy for lighting facilities in the parking area, as well as providing vegetation to help protect the environment.

- Expanding the pedestrian way, in areas with a road area below 10 meters width widening the pedestrian way 2-2.5 meters while on the road width of 10 meters widening the pedestrian way 3 meters.

- Provide the same cover element pattern to increase the connectivity of the open space as well as to give a striking color mark on specific areas including those in the area up and down the bus, crossing, garbage disposal areas and seating areas.

- Connecting the disability lane and widening the lane so that the disability is free to move and move in the open space of Lamongan downtown.

- Provide a special place between the body of the road and the pedestrian lane for the placement of street furniture and vegetation so that the pedestrian lane has an attractive and neat visuals.
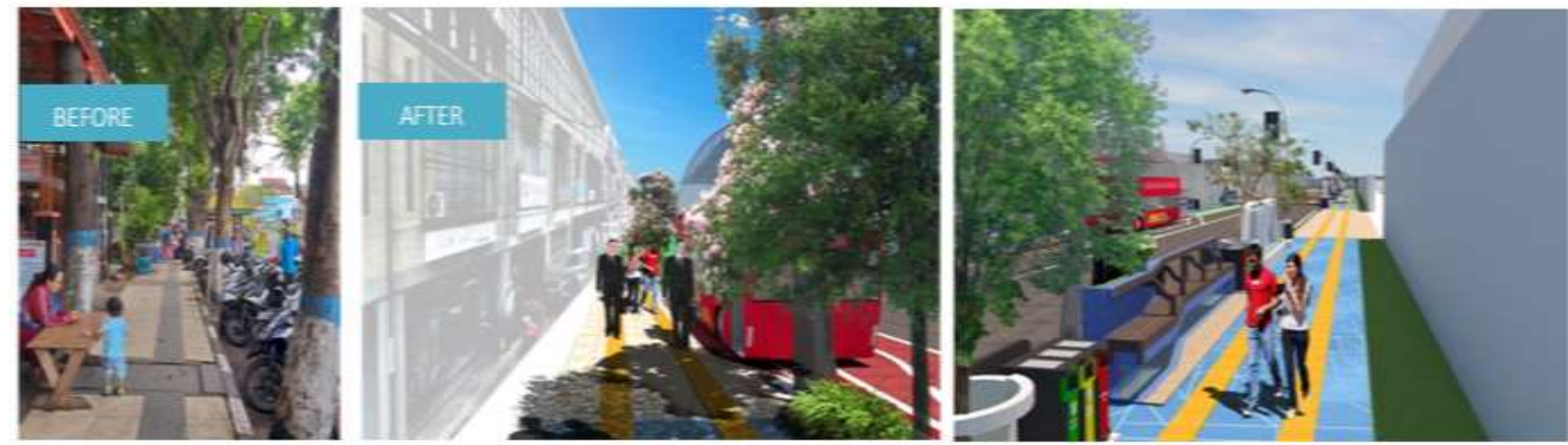

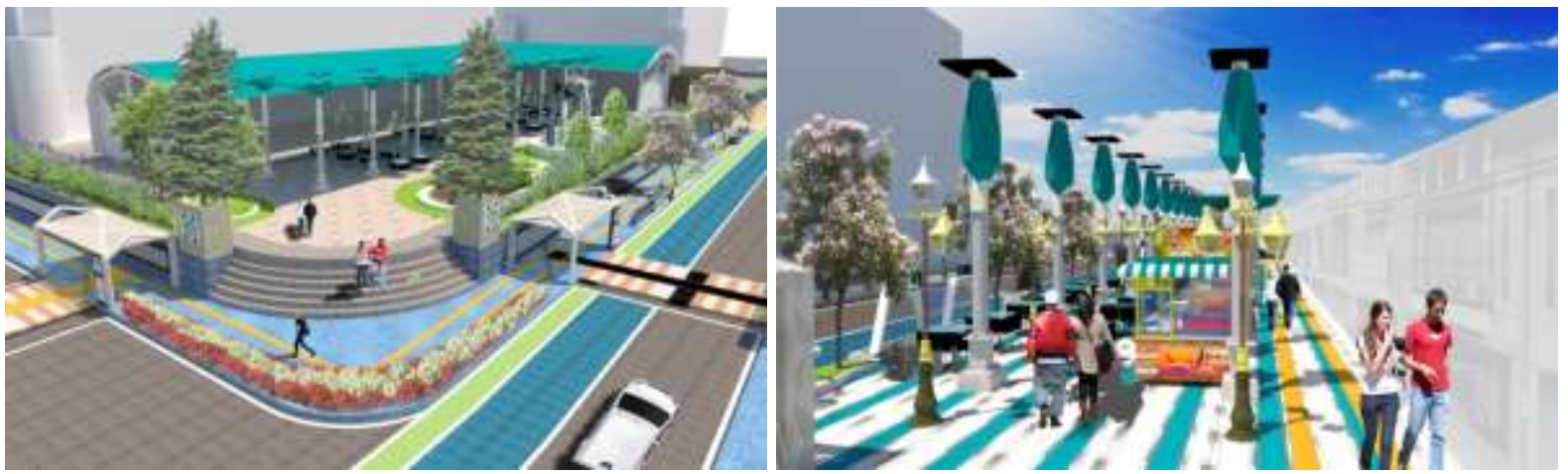

Utilization of Boulevard Road and former market parking area to be used as new space for street vendors so as not to disturb the mobility of vehicles and pedestrian mobility in the open space of the Lamongan City center, so that the open space in the city center can be maximally functional and has good and organized visuals

- Arrange crossing routes periodically, by applying a hydraulic system to lift sections of the body of the road that have cross ing paths, so that people are more comfortable especially people with disabilities with no difference in floor height between the crossing path and the pedestrian way.
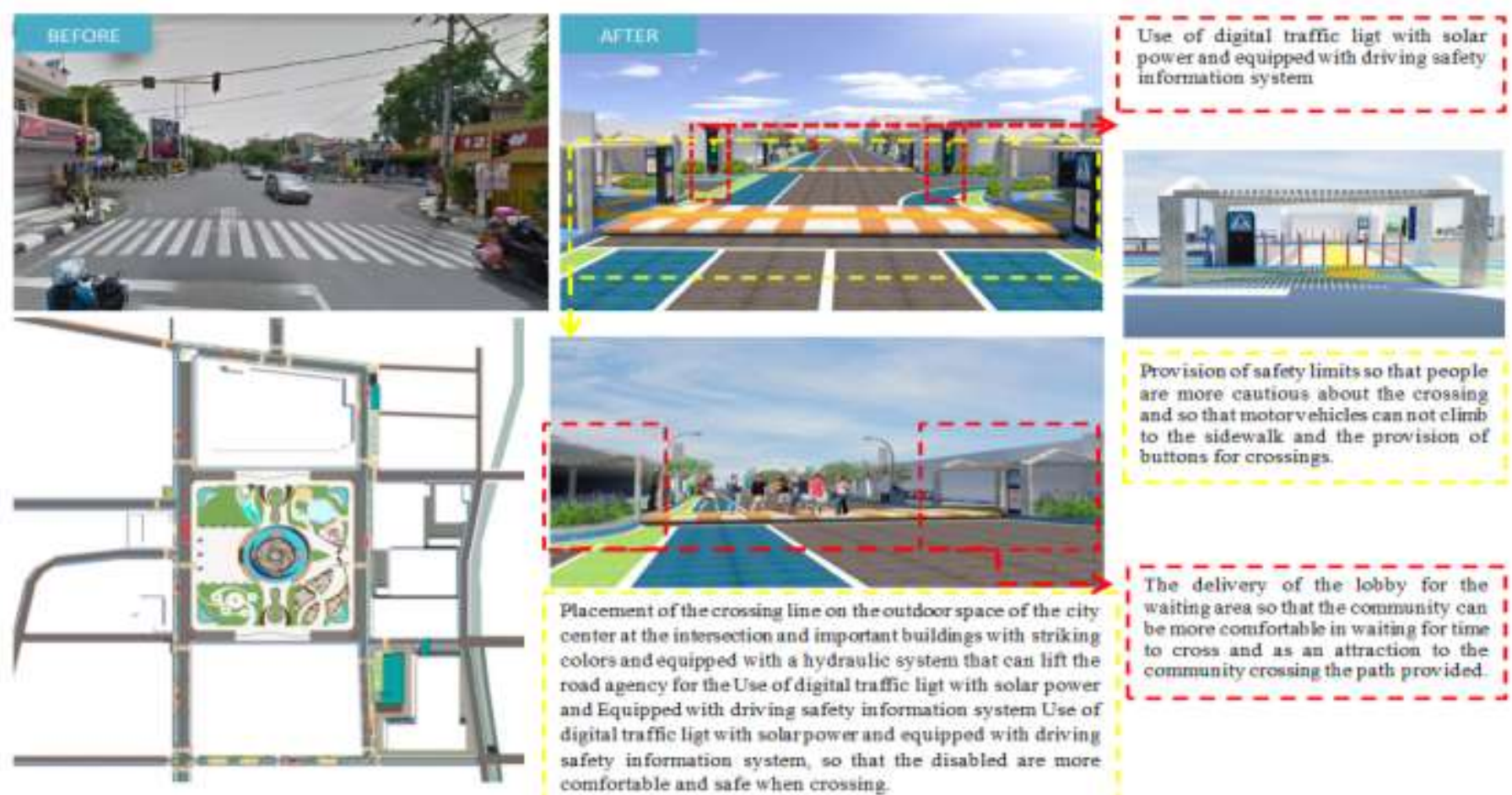

Provision of sa fety limits so that people are more cautious about the crosaing and so that motorvehicles can not clinib to the sidewalk and the provision of buttons for crossings.

The delivery of the lobby for the waiting ares so that the community can be more confortable in waiting for time 1 to eross and as an attraction to the comprity cressing the patt provided commonity ercssing the path provided. - $\ldots \ldots \ldots$

- Provide a monumental signage in the form of a statue of Bandung catfish and a fountain at the center of the open space, namely in the town square of Lamongan.

- Replacing plastic billboards with digital, so that plastic waste from previous advertisements will be reduced.

- The street lights use LED lights supported by solar thermal energy.

- Controlling waste periodically and utilizing sensors to show the volume of the trash bin to the public, so that the trash bin will not overload.

- Utilization of rainwater was tewater to support other elements in the open space of Lamongan downtown.

- Giving vegetation with beautiful colors namely, tabebuya, flamboyan, hibiscus and paper flowers. 


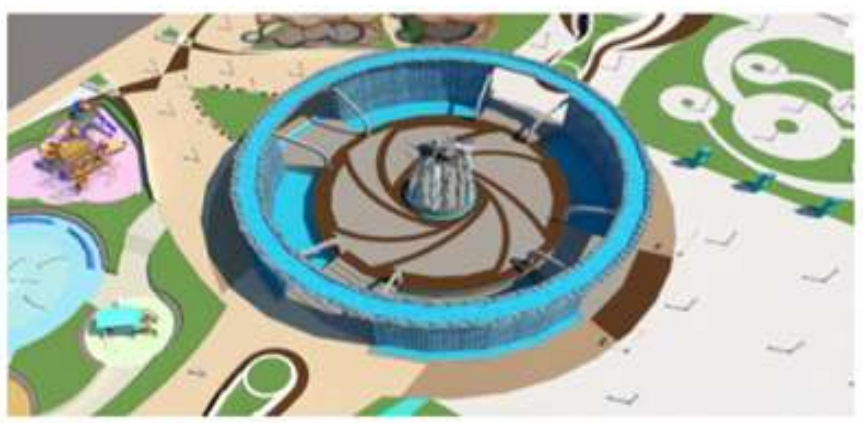

Providing signage with the sculpture milkfish that is a symbol of Lamongan city with water that is a character of Lamongan city as a water-dominated city, this signage utilizing the waste of rainwater, so that rainwater will be able to The temperature of Lamongan, which is quite high.
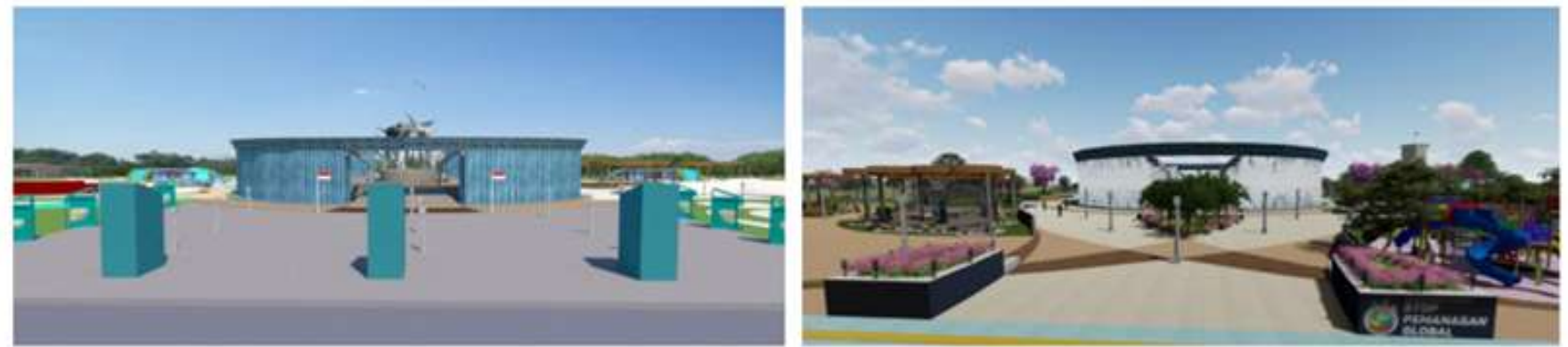

Furniture garden lamps are equipped with a temperature change sensor, when the city temperature rises to eat the furniture will convection water into the dew to reduce the temperature of heat in the space outside of the center of Lamongan, so that the community will be more comfortable when and have a good quality of life
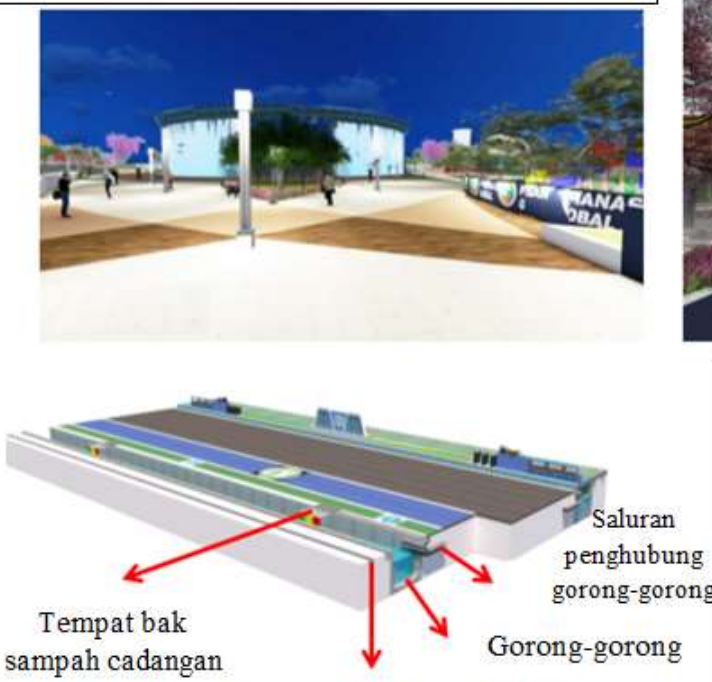
In waste water is stored on the sewers and utilized for the water overflow will be sent to the center of the shelter on the town square and on the river of the city, but also on the pedestrian section Way there is room for extra tub bins so that garbage is going to overload. Under the path of disability, you will be able to access space for the power cord, so that the power cord will not interfere with visual or other elements such as trees.

Penyimpanan kabel listrik 
Billboards on the Alaun is replaced with digital billboards and blends with the flowerpot, so billboards is more easily replaced by its supporters and reduces plastic waste. In addition, billboards can help with lighting outside the downtown area.

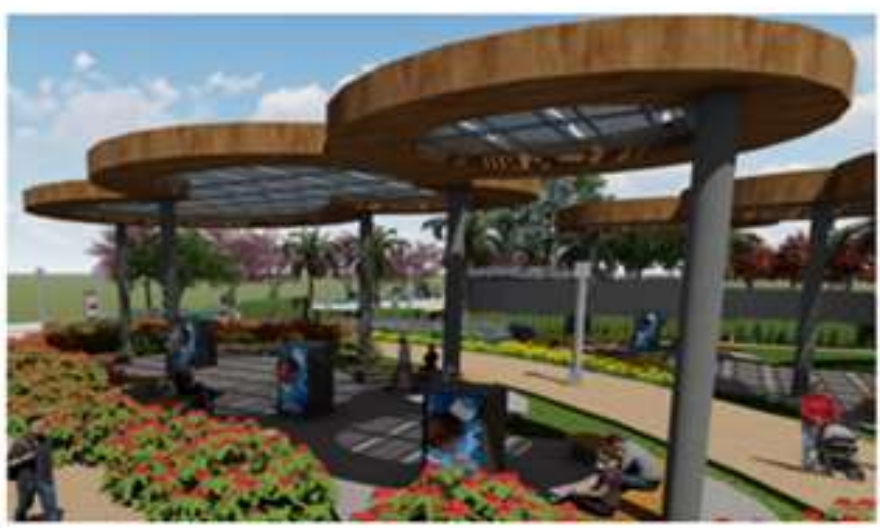

The provision of digital billboards on the rest of the community, to maximize the function of billboards as information and advertisement media

Furniture garden lamps are equipped with a temperature change sensor, when the city temperature rises to eat the furniture will convection water into the dew to reduce the temperature of heat in the space outside of the center of Lamongan, so that the community will be more comfortable when and have a good quality of life
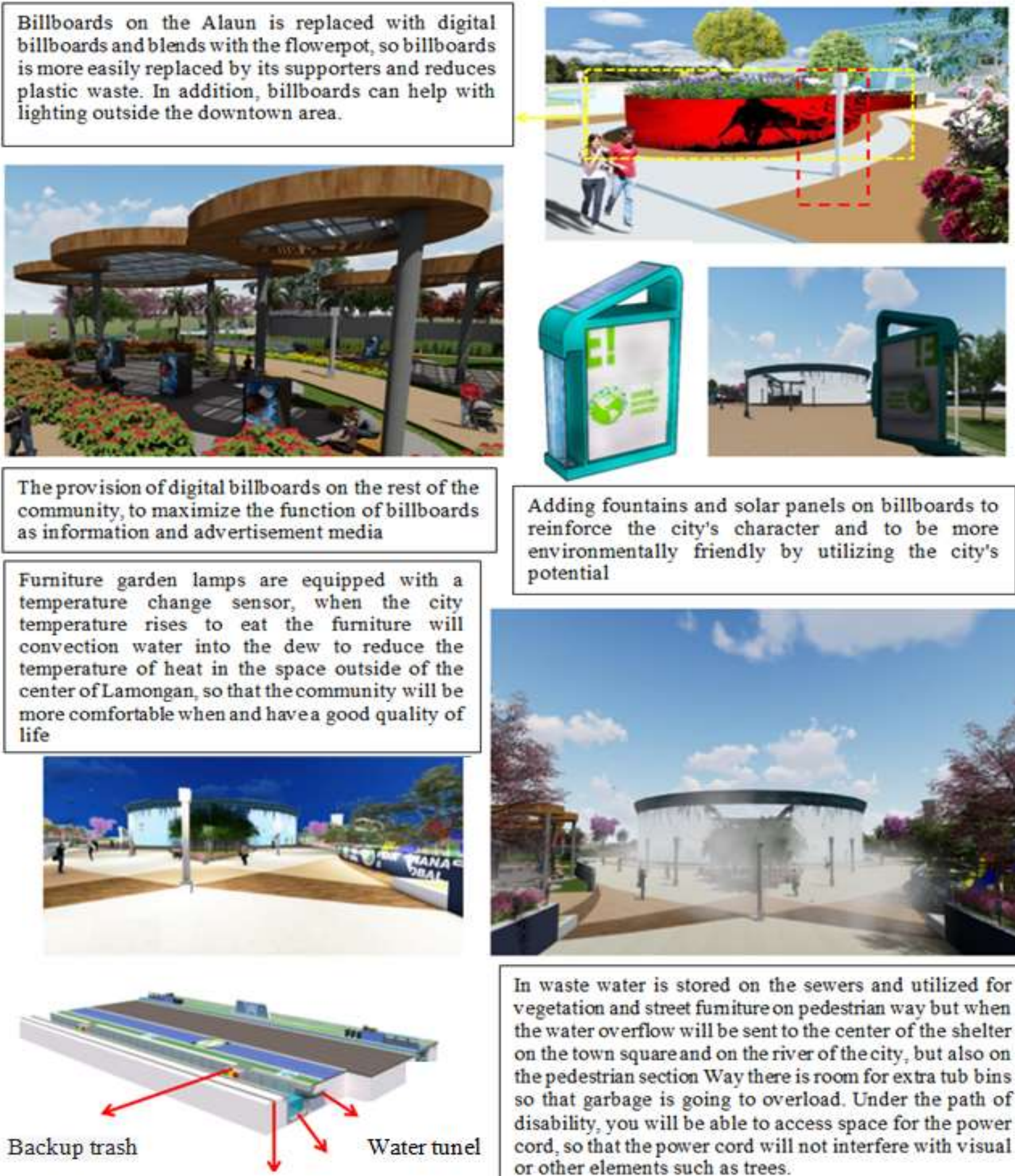

Adding fountains and solar panels on billboards to reinforce the city's character and to be more environmentally friendly by utilizing the city's potential

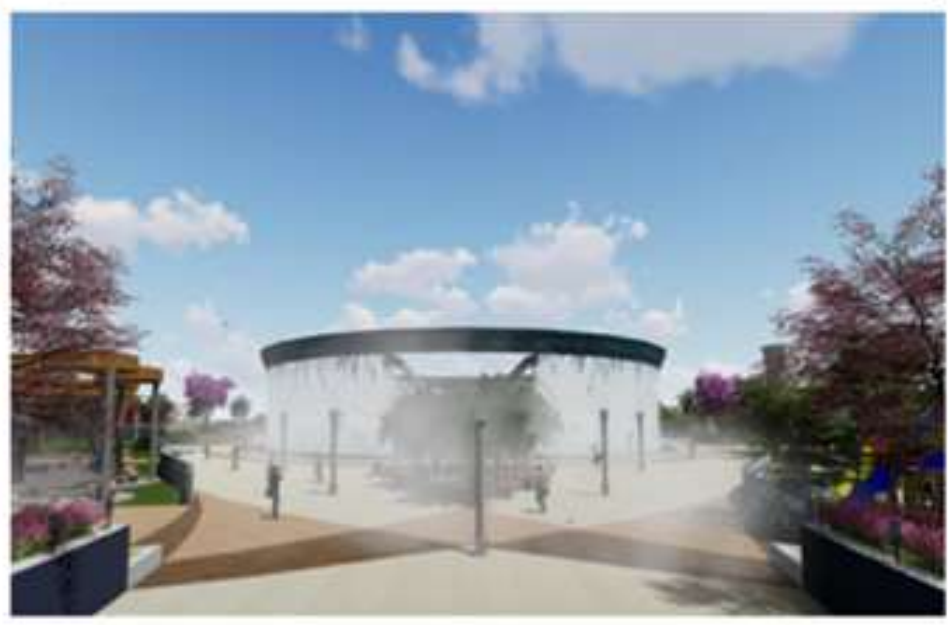

In waste water is stored on the sewers and utilized for vegetation and street fumiture on pedestrian way but when the water overflow will be sent to the center of the shelter on the town square and on the river of the city, but also on the pedestrian section Way there is room for extra tub bins so that garbage is going to overload. Under the path of disability, you will be able to access space for the power cord, so that the power cord will not interfere with visual or other elements such as trees.

Electric cable storage area

\section{CONCLUSION}

The results of the research indicate that there are several elements of the open space in the center of Lamongan City which can be arranged to optimize the function of the open space as a support for the development of the Lamongan City center which has quite high accessibility and activities as well as important buildings inside. The elements in the open space of Lamongan City center are: public transportation, road network systems, pedestrian paths, parking and intersection systems, Street furniture, green belts, waste management and energy utilization. The results of this research are the addition of environmentally friendly pub lic 
transportation by utilizing solar energy and its presence easily accessible to the community, the use of pedicabs that have environmentally friendly values and pedicabs are one of the work of the downtown community, connecting pedestrian paths and the division of two disability lanes to prevent collisions between persons with disabilities, the use of hydraulic systems to lift the road body that has crossing lanes so that people are safer and more comfortable to cross because there are no floor differences, providing ornamental plants that have striking colors namely flamboyant, tabebuya, paper flowers and hibiscus for open spaces, and implementing a sensor system to control rubbish waste and water waste, so that people will be more comfortable when doing activities in a clean and well-maintained open space and also the quality of the urban environment is getting better.

\section{ACKNOWLEDGMENT}

I would like to thanks the lecturers of the Sepuluh Nopember Institute of Technology Surabaya which has provided insights and suggestions so that this research can be completed well.

\section{REFERENCES}

[1] Klug, Stefan dan Hayashi, Yoshitsugu (2012). Urban Sprawl and Local Infrastructure in Japan and Germany. Journal of Infrastructure Systems ASCE 18(4): $232-241$.

[2] The long-term development plan of the District (RJRPD) of Lamongan. 2005-2015

[3] Lamongan signed to MOU, Jawa Pos newspaper. 10 May 2018. (accessed 10 May 2018. At 15 o'clock. 20 Wib)

[4] Shirvani, Hamid. (1985). The Urban Design Process. Van Nostrand Reinhold: New York

[5] Ashihara, Yoshinobu, Gunadi, S. (1974). "Exterior Design in Architecture" (translation). Faculty of ITS Architectural Engineering.

[6] Prabawasari. V.D., Suparman. A, (2009). Outside spatial 01. Gunadarma

[7] Hakim, R. (1993). Designing elements in Landscape architecture. Bumi Aksara. Jakarta.

[8] Trancik, R. (1986), Finding Lost Space: Theories of Urban Design, Van Nostrand Reinhold Co. Inc, New York

[9] Carr, Stephen, and others. (1992). Public Space, Cambridge University Press. USA

[10] Pratama, I Putu Agus. (2014) Smart City (benefits, implementation, and security). Seminar of Universitas Langlangbuana Bandung. In the guest lecture papers with themes: towards Smart City concept 1, by; Shinta Esabella, S.T., M. TI

[11] Susanto, Tony D. (2019), SMART CITY concept, Model and Technology, Indonesian Information Systems Association (AISINDO), Surabaya

[12] Giffinger, R., Fertner, C., Kramar, H., Kalasek, R., Pichler-Milanovi, N., \& Meijers, E. (2007). Smart Cities: Ranking of European Medium-Sized Cities. Vienna, Austria: Centre of Regional Science (SRF), Vienna University of Technology.

[13] Darjosanjoto.(2012). Architectural Research in the Field of Housing and Settlements. 2nd edition. ITS Press. Surabaya

[14] Groat, L., and Wang, D, (2002). Architectural Research Method. John Wiley Son, Inc.

[15] Ministry for the Environment (2009), Urban Design Toolkit (Third Edition), Wellington, New Zealand

[16] Thomas R, Aidala, A.I.A. (1970), Urban Design Principles for San Francisco, San Francisco Departement of City Planning. San Francisco

[17] Urban Systems Research \& Engineering, (1977), An assessment of admissions criteria for bilingual/bicultural applicants to health professions schools. [Washington]: U.S. Dept. of Health, Education, and Welfare, Public Health Service, Health Resources Administration, Bureau of Health Manpower., Lynch, Kevin. (1981). A THEORY OF GOOD CITY FORM, MIT Press, USA,

[18] Moughtin, C. (1999). Method and Techniques. British Library Cataloguing in Publication 